ISSN 2179-345X

Licenciado sob uma Licença Creative Commons

\title{
Capitalismo Humanista: uma aplicação da justiça econômica?
}

\author{
Humanist Capitalism: does it apply \\ to the economic justice?
}

\section{Fernanda Tatari Frazão de Vasconcelos Bressane}

Mestranda em Direitos Difusos e Coletivos pela Pontifícia Universidade Católica de São Paulo (PUC-SP), defensora pública do Estado de São Paulo, São Paulo - Brasil, e-mail: fernandatfv@uol.com.br

\section{Resumo}

A adoção dos preceitos existentes na obra de Jacques Maritain, propugnados especialmente em seu livro Humanismo integral, publicado em Paris no ano de 1936, desencadeou o desenvolvimento recente de uma nova concepção de teoria jurídica econômica, denominada "Capitalismo Humanista". O presente artigo busca fazer um paralelo entre essa teoria e o conceito de justiça econômica, que aplica valores morais e éticos à sociedade de mercado, mediante observância da justiça comutativa e da justiça distributiva. Sob a ótica religiosa católica, a justiça econômica pode se confundir com a opção preferencial pelos pobres. Pretende-se verificar se as 
relações econômicas, ao atenderem à realização máxima dos direitos humanos, necessariamente também contemplarão os postulados da justiça econômica.

Palavras-chave: Justiça econômica. Justiça comutativa. Capitalismo Humanista. Justiça distributiva.

\section{Abstract}

The adoption of the principles existent in Jacques Maritain's body of work, defended especially in his book Integral humanism (Paris, 1936), brought about the recent development of a new conception of a legal economic theory called "Humanist Capitalism". The main focus of this article is to compare the theory of Humanist Capitalism and the definition of economic justice, which applies moral values and ethics to the market society through the observance of commutative justice and distributive justice. Under the approach of the catholic religion, economic justice can be confused with a preferred choice for the poor. The intent is to verify whether or not economic relations, when in full realization of Human Rights, will necessarily contemplate the postulates of economic justice.

Keywords: Economic justice. Commutative justice. Humanist Capitalism. Distributive justice.

\section{A definição histórica de justiça econômica}

A definição de justiça econômica remonta à Antiguidade Grega e foi primeiramente desenvolvida por Aristóteles. A partir da Idade do Ferro, por volta de 1200 a.C., com o aumento significativo da produção dos artesãos, decorrente da nova tecnologia, surgiu um mercado impessoal diferente do antigo escambo realizado.

Na mesma direção, as transações monetárias também se incrementaram e o antigo comércio local se expandiu para lugares mais longínquos. Como consequência dessa expansão territorial dos mercados, verificou-se um efeito desagregador nas sociedades. 
A concentração de riqueza nas mãos dos comerciantes acabou por gerar um conflito de interesses entre estes e a classe dominante, enquanto os camponeses empobrecidos, esvaziados de sua anterior função, passaram a reagir de forma negativa.

Segundo o cientista político canadense Crawford Brough Macpherson, tais acontecimentos culminaram na formulação da justiça econômica. Confira-se:

Aristóteles foi o primeiro a fazer distinção entre uma economia de mercado simples e, na qual a produção e a troca visavam ao mero consumo, e uma economia de mercado mais complexa, na qual a troca era iniciada pelo comerciante, que usava seu capital para comprar e depois vender com lucro, aumentando assim a sua riqueza, sistema em que "o dinheiro é o ponto de partida e o objetivo da troca”. Ele viu que a sociedade já estava bastante adiantada nesse processo de transição de uma economia de mercado simples para outra mais complexa. E, baseado num argumento ético, condenou esta última como destruidora da vida digna. Chamou-a de antinatural por três motivos: ela torna a aquisição um fim em si mesmo e não um meio para a vida digna; o processo de acumulação não tem limites, ao passo que a vida digna requer apenas recursos materiais limitados; ela é um meio pelo qual alguns homens ganham, à custa de outros, o que é injusto (MACPHERSON, 1991, p. 18-19).

Seguindo na lição de Aristóteles, a justiça econômica funda-se na autonomia das relações econômicas, vista com independência das relações sociais e políticas, assim como é calcada na transposição dos valores éticos e morais às relações econômicas, partindo da máxima de que o homem detém natureza social. Macpherson (1991) nos ensina, ainda, que a justiça econômica possui princípios peculiares e próprios em relação à justiça geral.

Uma característica essencial da justiça econômica seria o "preço justo", isto é, o equilíbrio nas trocas mercantis para que os valores relativos às mercadorias e aos serviços não dependam exclusivamente do mercado, da oferta e procura, e sejam estabelecidos por meio das tradições e dos costumes da sociedade. 
Trata-se da expressão da justiça comutativa no âmbito da economia, que é muito semelhante ao conceito propugnado por Santo Tomás de Aquino durante a Idade Média, à exceção de que, em contrapartida a Aristóteles, admitia a percepção de lucro pelo comerciante, desde que este não ultrapassasse o valor real de sua atividade.

Outra face da justiça econômica, que se desenvolve pela tradução da justiça distributiva, seria a divisão do produto global entre os integrantes da sociedade, a fim de evitar a acumulação de riquezas de um lado e não comprometer a subsistência dos menos favorecidos de outro.

André Franco Montoro (2000, p. 152) distingue bem os conceitos de justiça comutativa e distributiva ao afirmar que:

na justiça distributiva e na social há, também, um "devido", propriamente dito, que pode ser exigido pelo interessado. Mas na comutativa esse "devido" é mais rigoroso, porque se trata de assegurar à pessoa o respeito a um direito que já lhe é "próprio", como sua integridade física, sua dignidade, seus bens. A justiça comutativa versa sobre o que é de cada pessoa "por direito próprio", diz Vermeersch.

$\mathrm{Na}$ distributiva, pelo contrário, deve-se repartir entre particulares aquilo que é "comum". Da mesma forma, na justiça social trata de deveres em relação ao bem "comum".

E, como diz S. Tomás, dever a alguém um bem "comum", é coisa diferente de lhe dever um bem que lhe é "próprio'." Quando se distribui entre os membros da comunidade um bem comum, cada um recebe, "de certa forma” (aliquo modo), o que é seu. Na comutativa, como vimos, o devido à pessoa não é seu, apenas "de certa forma" mas em sentido direto e próprio.

Durante a maior parte da Idade Média, antes do início das Cruzadas, não havia a figura da produção excedente e o comércio era incipiente, principalmente por dois motivos: a) as distâncias eram maiores e havia escassez dos meios de transporte; b) a moeda não era comum, tampouco largamente utilizada, bem como não havia uniformidade nos indexadores de pesos e medidas. 
Para se ter noção da natureza dos escambos durante a Idade Média, é importante o escólio de Leo Huberman (2010, p. 14):

sem dúvida, havia um certo intercâmbio de mercadorias. Alguém podia não ter lã suficiente para fazer seu casaco, ou talvez não houvesse na família alguém com bastante tempo ou habilidade. Nesse caso, a resposta à pergunta sobre o casaco poderia ser: "Paguei cinco galões de vinha por ele". Essa transação provavelmente se efetuou no mercado semanal mantido junto de um mosteiro ou castelo, ou numa cidade próxima. Esses mercadores estavam sob o controle do bispo ou senhor e ali se trocavam quaisquer excedentes produzidos por seus servos ou artesãos ou quaisquer excedentes dos servos. Mas com o comércio em tão baixo nível não havia razão para a produção de excedentes em grande escala.

Só se fabrica ou cultiva além da necessidade de consumo quando há uma procura firme. Quando não há essa procura, não há incentivo à produção de excedentes. Assim sendo, o comércio nos mercados semanais nunca foi muito intenso e era sempre local. Um outro obstáculo à sua intensificação era a péssima condição das estradas. Estreitas, malfeitas, enlameadas e geralmente inadequadas às viagens. E ainda mais, eram frequentadas por duas espécies de salteadores-bandidos comuns e senhores feudais que faziam parar os mercadores e exigiam que pagassem direitos para trafegar em suas estradas abomináveis. A cobrança do pedágio era uma prática tão comum que "quando Odo de Tours, no século XI, construiu uma ponte sobre o Loire e permitiu o livre trânsito. sua atitude provocou assombro".

Outros obstáculos retardavam a marcha do comércio. O dinheiro era escasso e as moedas variavam conforme o lugar. Pesos e medidas também eram variáveis de região para região. O transporte de mercadorias para longas distâncias, sob tais circunstâncias, obviamente era penoso, perigoso, difícil e extremamente caro. Por todos esses motivos, era pequeno o comércio nos mercados feudais locais.

Do texto transcrito, destaca-se que, embora reconhecido o pequeno porte do comércio na alta Idade Média, havia controle exercido pelo bispo ou senhor feudal, pelo que se conclui que tais relações mercantis eram extremamente limitadas. 
Ademais, não se pode esquecer que a grande potência da Idade Média era a Igreja, que condenava a cobrança de juros pelo empréstimo de dinheiro. As obras literárias da época refletiram com veemência a repulsa a tal prática, como se verifica, por exemplo, no Mercador de Veneza, de autoria de William Shakespeare.

As Cruzadas, sob o falso propósito de difundir o Evangelho, tinham essencial caráter comercial e, associadas às subsequentes grandes navegações, acabaram por reiniciar a prática comercial. Macpherson (1991) estabelece que Thomas Hobbes teria proclamado em 1651 o fim da justiça econômica, com o consequente reconhecimento de uma nova ordem mercantil.

Assim, o mundo caminhou para a economia de mercado, especialmente após a revolução industrial, e os conceitos de justiça comutativa e distributiva foram levados para segundo plano.

Apenas no século XX, tais valores foram efetivamente resgatados, primordialmente nas democracias liberais. Pode-se dizer que após 1929, com as medidas estatais de intervenção na economia e previsão de direitos sociais, tais premissas tornaram a ser difundidas, constituindo, inclusive, plataforma política, especialmente dos adeptos da social-democracia.

\section{A Doutrina Social da Igreja e a justiça econômica}

Os valores cristãos, na qualidade de crença religiosa mundialmente mais professada, são imanentes à civilização ocidental e calcados na máxima de amor ao próximo.

A Doutrina Social da Igreja busca fixar princípios e diretrizes gerais aos cristãos católicos, desenvolvendo-se primordialmente no século XIX com o escopo de ser instrumento de evangelização na tentativa de levar o homem para a sua salvação. É composta pelas encíclicas e pronunciamentos dos papas ao longo da história e teve maior expressão após a modificação das relações de produção e de trabalho, urgindo para 
o papa Leão XII, em 1891, conhecedor da natureza das dificuldades advindas da situação econômica mundial, a elaboração da encíclica Rerum Novarum, questionando a situação das classes trabalhadoras após a revolução industrial.

Considerando tal missão, os bispos americanos durante a Conferência Nacional dos Bispos Católicos Americana, no ano de 1986, aprovaram a carta pastoral denominada Justiça econômica para todos. A síntese do conteúdo da carta pastoral foi descrita magistralmente pelo Mestre em Teologia Social padre Edson Donizeti Toneti (2011) e guarda relação direta com os princípios da justiça econômica, que é o tema central deste trabalho. Vejamos:

o tema principal debatido pelos Bispos Americanos, repetido ao longo de todo o ofício pastoral, foi claro ao dizer que o governo federal devia gastar menos dinheiro na defesa nacional e mais com os pobres. Além disso, o desemprego e a consequente erosão da estabilidade das estruturas familiares configuravam problemas que ameaçavam a dignidade e o bem-estar das pessoas não só nos U.S., mas por todas as partes do mundo. Esta carta pastoral também fez uma forte condenação do racismo como um pecado que divide a família humana. Neste diapasão, os Bispos Americanos relacionaram a situação econômica à sua carta pastoral anterior sobre a paz, lamentando o montante de fundos gastos em armas. Refletindo sobre questões econômicas no âmbito internacional, os bispos incluíram recomendações para a reforma do Banco Mundial, o Fundo Monetário Internacional, e considerações a respeito do Acordo Geral sobre Tarifas e Comércio. Assim, os Bispos procuram construir um novo espírito de cooperação e uma nova visão do que o ideal de justiça econômica exige para toda a sociedade. A carta pastoral Justiça econômica para todos afirma que "o elo comum da humanidade que liga todas as pessoas é a fonte da nossa convicção de que o país possa atingir uma renovada visão moral pública." A origem deste elo comum é a mensagem bíblica que há um Deus que é criador do céu, da terra e da família humana. O núcleo desta nova visão moral é o conceito de dignidade humana. Neste sentido, as instituições sociais devem ser construídas de forma a garantir que os indivíduos tenham acesso aos bens materiais mínimos e tenham asseguradas as 
relações interpessoais e as liberdades fundamentais, que são indispensáveis para a sua participação na vida social. Quando a economia nega os direitos básicos que nutrem e protegem a dignidade humana que prejudica o indivíduo, ela fere também a comunidade como um todo. Considerando o fato de que a sociedade deve atender às necessidades básicas de todos, os Bispos Americanos dirigiram implicativas palavras sobre justiça básica, que é o fundamento da relação entre a dignidade humana e a vida social.

Justiça básica exige o estabelecimento de níveis mínimos de participação na vida da comunidade humana para todas as pessoas. A finalidade última da injustiça é tratar ativamente ou abandonar passivamente uma pessoa ou grupo como se não fossem membros da raça humana. Tratar as pessoas desta forma é efetivamente dizer que elas simplesmente não contam como seres humanos.

As exigências de justiça são que asseguram para cada pessoa humana o bem-estar e a dignidade, promovendo as condições sociais para que isto seja uma realidade possível. Ao assumir isto, os Bispos Americanos manifestaram o desejo de desenvolver um espírito de cooperação e de compromisso que são necessários para transformar os problemas econômicos enfrentados pelos U.S. e vários outros países do mundo, especialmente no "Terceiro Mundo." Talvez um meio de maximizar a dignidade humana seria proteger a capacidade de todas as pessoas para agir em seu próprio interesse. Os subsídios e o bem-estar públicos são necessários para lidar com os efeitos da injustiça, sendo que a sociedade sempre necessitará providenciar o cuidado dos que são física e mentalmente prejudicados. Mas a preocupação no resgate da dignidade das pessoas, exige que todos tenham oportunidades através da educação e capacitação profissional, para assumir a responsabilidade pelo seu próprio bem-estar. Em uma sociedade economicamente justa e igualitária a meta não seria ajudar os pobres, mas sim garantir a sua capacidade para ajudar a si mesmos e abandonar as fileiras da pobreza uma autonomia digna.

O artigo colacionado frisa a relevância da igualdade de oportunidades, mais do que a caridade por si só. A opção pelos pobres permanece guiando a fé e a conduta cristã, porém, a carta pastoral foi mais além ao dizer que a dignidade humana só seria constatada na medida em que se 
provesse educação e capacitação profissional, conferindo autonomia ao destinatário para que possa assegurar o próprio bem-estar.

De conseguinte, vê-se que a Igreja, embora não tenha aderido ao capitalismo ou ao socialismo como sistema econômico, manifestamente é partidária da justiça econômica.

\section{As mazelas do capitalismo liberal}

A principal e latente consequência natural da adoção do sistema capitalista são as desigualdades geradas pelo acúmulo de riqueza, enquanto parcela expressiva da sociedade se vê alijada do mercado de consumo.

A desproporção na distribuição de renda é o mais cruel efeito, porquanto aperfeiçoa dificuldades periféricas como a violência e a própria luta de classes. Com a falha na divisão de riquezas, por não se observar a justiça distributiva, André Franco Montoro (2000, p. 175) enumera os danos atualmente vislumbrados da seguinte forma:

nesse sentido, examinamos em estudo anterior as principais violações da justiça distributiva na vida social contemporânea:

a) o desnível entre nações industrializadas e nações subdesenvolvidas, dentro da comunidade mundial.

b) o desnível entre regiões de um mesmo país, de que é exemplo, no Brasil, a desigualdade de condições entre o Norte, o Nordeste e o Centro-Sul;

c) o desnível entre os setores econômicos: primário (agricultura e mineração), secundário (indústria) e terciário (serviços: comércio, bancos, profissões liberais, ensino, serviço público).

d) o desnível entre classes sociais. "São muitos os homens que sofrem e aumenta a distância que separa o progresso de uns da estagnação e, até mesmo, do retrocesso de outros".

Esse quadro revela o caráter dinâmico, a gravidade e a importância das exigências da justiça distributiva no mundo contemporâneo. E põe em evidência um dos aspectos do grande imperativo do "desenvolvimento 
com justiça”, proclamado pela Conferência das Nações Unidas sobre Comércio e Desenvolvimento.

Celso Furtado (2009, p. 269), por sua vez, descreve bem como a crise mundial de 1929 , que se considera o maior colapso do sistema capitalista, foi sofrida no Brasil:

vejamos em primeiro lugar como operou o mecanismo clássico de defesa através da taxa cambial. A grande acumulação de estoques de 1929, a rápida liquidação das reservas metálicas brasileiras e as precárias perspectivas de financiamento das grandes safras previstas para o futuro aceleraram a queda do preço internacional do café iniciada conjuntamente com a de todos os produtos primários em fins de 1929. Essa queda assumiu proporções catastróficas, pois, de setembro de 1929 a esse mesmo mês de 1931, a baixa foi de 22,5 centavos de dólar por libra para 8 centavos. Dadas as características da procura do café, cujo consumo não baixa durante as depressões nos países de elevadas rendas, essa tremenda redução de preços teria sido inconcebível sem a situação especial que se havia criado do lado da oferta. Basta ter em conta que o preço médio pago pelo consumidor norte-americano, entre 1929 e 1931, baixou apenas de 47,9 para 32,8 centavos por libra159. Acumularam-se, portanto, os efeitos de duas crises: uma do lado da procura e outra do lado da oferta. A situação favoreceu as organizações intermediárias no comércio do café, as quais, percebendo a debilidade da posição da oferta, puderam transferir para os produtores brasileiros grande parte de suas perdas causadas pela crise geral.

A baixa brusca do preço internacional do café e a falência do sistema de conversibilidade acarretaram a queda do valor externo da moeda. Essa queda trouxe, evidentemente, um grande alívio ao setor cafeeiro da economia. A baixa do preço internacional do café havia alcançado 60 por cento. A alta da taxa cambial chegou a representar uma depreciação de 40 por cento160. O grosso das perdas poderia, portanto, ser transferido para o conjunto da coletividade através da alta dos preços das importações. 
Soa absurdo pensar que parte da produção de café à época da grande depressão teve que ser destruída, mas, como bem assinalou o economista, tratava-se de um mecanismo de defesa do capitalismo contra si mesmo.

Como bem lembra a lição de Ricardo Hasson Sayeg, têm-se como características negativas do capitalismo, na sua forma atual, a tendência à corrupção governamental, a primazia desmesurada do individualismo, a miséria, o esgotamento dos recursos naturais, em suma, "a exclusão de parcela substancial da Humanidade do circuito econômico, político, social e cultural, colocando-a à mercê do flagelo da fome, da miséria, da subjugação e da alienação mental" (SAYEG, 2010, p. 14).

\section{Características da justiça distributiva e da justiça comutativa na sociedade contemporânea}

A herança dos postulados da justiça comutativa nos dias hodiernos é amplamente verificada, em especial no campo contratual. Recentes diplomas legais preveem cada vez mais o equilíbrio dos contratos em contrapartida à ideia da pacta sunt servanda.

Muitos dos comandos normativos foram criados exatamente visando a contemplar o "preço justo" a que se referia Aristóteles, de forma a evitar a onerosidade excessiva e criar valores que fogem ao campo econômico.

A começar pela Lei Federal n. 8.078/90, instituidora do Código de Defesa do Consumidor, que preceitua a possibilidade de alteração de prestações extremamente desvantajosas, que desfavoreçam o consumidor, a fim de primar pela manutenção da razoabilidade (BRASIL, 1990). Confira-se:

Art. $6^{\circ}$ São direitos básicos do consumidor:

[...]

V - a modificação das cláusulas contratuais que estabeleçam prestações desproporcionais ou sua revisão em razão de fatos supervenientes que as tornem excessivamente onerosas; 
Com efeito, o direito contratual brasileiro também se orienta conforme a justiça comutativa, tanto é que a legislação consumerista prevê de forma expressa a nulidade de cláusulas abusivas.

Da leitura do comando do artigo 51 do Código de Defesa do Consumidor, depreendem-se vários critérios de proteção à parte mais vulnerável do contrato, em especial a preservação do equilíbrio, a vedação a prestações que se tornem excessivamente onerosas e a possibilidade do reembolso. Importante, nessa senda, a transcrição do citado dispositivo:

Art. 51. São nulas de pleno direito, entre outras, as cláusulas contratuais relativas ao fornecimento de produtos e serviços que:

I - impossibilitem, exonerem ou atenuem a responsabilidade do fornecedor por vícios de qualquer natureza dos produtos e serviços ou impliquem renúncia ou disposição de direitos. Nas relações de consumo entre o fornecedor e o consumidor pessoa jurídica, a indenização poderá ser limitada, em situações justificáveis;

II - subtraiam ao consumidor a opção de reembolso da quantia já paga, nos casos previstos neste código;

III - transfiram responsabilidades a terceiros;

IV - estabeleçam obrigações consideradas iníquas, abusivas, que coloquem o consumidor em desvantagem exagerada, ou sejam incompatíveis com a boa-fé ou a equidade;

$\mathrm{V}$ - (Vetado);

VI - estabeleçam inversão do ônus da prova em prejuízo do consumidor; VII - determinem a utilização compulsória de arbitragem;

VIII - imponham representante para concluir ou realizar outro negócio jurídico pelo consumidor;

IX - deixem ao fornecedor a opção de concluir ou não o contrato, embora obrigando o consumidor;

$\mathrm{X}$ - permitam ao fornecedor, direta ou indiretamente, variação do preço de maneira unilateral;

XI - autorizem o fornecedor a cancelar o contrato unilateralmente, sem que igual direito seja conferido ao consumidor;

XII - obriguem o consumidor a ressarcir os custos de cobrança de sua obrigação, sem que igual direito lhe seja conferido contra o fornecedor; XIII - autorizem o fornecedor a modificar unilateralmente o conteúdo ou a qualidade do contrato, após sua celebração; 
XIV - infrinjam ou possibilitem a violação de normas ambientais;

XV - estejam em desacordo com o sistema de proteção ao consumidor; XVI - possibilitem a renúncia do direito de indenização por benfeitorias necessárias.

$\S 1^{\circ}$ Presume-se exagerada, entre outros casos, a vontade que:

I - ofende os princípios fundamentais do sistema jurídico a que pertence;

II - restringe direitos ou obrigações fundamentais inerentes à natureza do contrato, de tal modo a ameaçar seu objeto ou equilíbrio contratual; III - se mostra excessivamente onerosa para o consumidor, considerando-se a natureza e conteúdo do contrato, o interesse das partes e outras circunstâncias peculiares ao caso.

$\S 2^{\circ}$ A nulidade de uma cláusula contratual abusiva não invalida o contrato, exceto quando de sua ausência, apesar dos esforços de integração, decorrer ônus excessivo a qualquer das partes.

Como outros corolários da justiça comutativa, objetivando o equilíbrio das relações contratuais, podem ser citados os princípios trazidos pela Lei Federal n. 10.406/02, estabelecendo o Código Civil de 2002, que inovou o ordenamento pátrio ao estabelecer a boa-fé objetiva, a função social dos contratos e a eticidade, como norteadores dos negócios jurídicos (BRASIL, 2002).

Na mesma direção, é de se lembrar que a Parte Geral do Código Civil estabelece como defeitos do negócio jurídico a lesão e o estado de perigo. Tais institutos visam a evitar que sejam determinadas prestações desproporcionais, assumidas em função de circunstâncias emergenciais.

Os comandos normativos que disciplinam o estado de perigo e a lesão dizem respectivamente que o dever desproporcional contraído adveio "da necessidade de salvar-se, ou a pessoa de sua família" ou "sob premente necessidade, ou por inexperiência" (BRASIL, 2002).

Trata-se, portanto, de reflexões da justiça econômica que passaram a integrar a lei brasileira, como forma de evitar que as práticas comerciais sejam guiadas tão somente pelas regras de mercado.

No que diz respeito à justiça distributiva, verifica-se que há políticas públicas fortemente influenciadas nas suas premissas, a começar 
pela famigerada bolsa família. Nas palavras de Macpherson (1991), os preceitos da justiça distributiva são vastamente defendidos pelos países de Terceiro Mundo que ambicionam o desenvolvimento econômico para elevarem-se à categoria daqueles de Primeiro Mundo, bem como se tornou bandeira dos partidos social-democratas.

No campo do Direito Previdenciário, destaca-se o firme propósito de redistribuição de renda, em especial levando em conta os benefícios assistenciais existentes. De fato, a Constituição Federal de 1988 (BRASIL, 1988), chamada comumente de Constituição Cidadã, por encerrar um período de ditadura militar e inaugurar a ordem democrática, teve, entre seus incomensuráveis méritos, a universalização da previdência social, nos moldes dos artigos a seguir transcritos:

Art. $6^{\circ}$ São direitos sociais a educação, a saúde, a alimentação, o trabalho, a moradia, o lazer, a segurança, a previdência social, a proteção à maternidade e à infância, a assistência aos desamparados, na forma desta Constituição

Art. 194. A seguridade social compreende um conjunto integrado de ações de iniciativa dos Poderes Públicos e da sociedade, destinadas a assegurar os direitos relativos à saúde, à previdência e à assistência social.

Parágrafo único. Compete ao Poder Público, nos termos da lei, organizar a seguridade social, com base nos seguintes objetivos:

I - universalidade da cobertura e do atendimento;

II - uniformidade e equivalência dos benefícios e serviços às populações urbanas e rurais;

III - seletividade e distributividade na prestação dos benefícios e serviços;

IV - irredutibilidade do valor dos benefícios;

$\mathrm{V}$ - equidade na forma de participação no custeio;

VII - caráter democrático e descentralizado da administração, mediante gestão quadripartite, com participação dos trabalhadores, dos empregadores, dos aposentados e do Governo nos órgãos colegiados. 
Embora as providências tomadas pelo constituinte tenham acarretado dificuldades na administração do erário público e do Tesouro Nacional, não se pode negar que, ao mesmo tempo, criou oportunidades de acesso àqueles esquecidos pelo ordenamento anterior.

Logo, em que pesem as vozes contrárias que afirmam que a justiça econômica está fadada ao desaparecimento, sua presença é sentida cada vez mais no ordenamento jurídico brasileiro.

\section{A humanização da economia de mercado e a justiça econômica}

Por certo, ao trazer valores e ética às relações comerciais, especialmente considerando o "preço justo" e a equânime distribuição de renda, tem-se que a adoção da justiça econômica, natural e implicitamente, acarretaria garantir de forma mais ampla os direitos humanos.

Vários dispositivos do Pacto Internacional dos Direitos Econômicos, Sociais e Culturais, ratificado pelo Brasil em 1992 por intermédio do Decreto n. 678/92, dizem respeito à implementação de princípios da justiça econômica (BRASIL, 1992).

Ressalta-se que todos os direitos enunciados pelo referido diploma legal constituem preceitos jurídicos obrigatórios e vinculantes aos signatários, sendo a desobediência aos ditames passível de responsabilização internacional. A título de exemplo, consigna-se a proteção ao trabalho e à justa remuneração, o direito a um nível adequado de vida, o direito à educação etc.

Uma das facetas da justiça econômica é a justiça distributiva, que exige "que toda a família tivesse a renda necessária para uma vida digna, a quantia que permitisse a cada uma combinar temperança com liberalidade" (MACPHERSON, 1991, p. 19). Isso significa que garantir a dignidade da pessoa humana é a principal meta da justiça distributiva, que, por sua vez, é um requisito para que se efetive a justiça econômica.

A dignidade da pessoa humana constitui princípio fundamental, conforme dispositivo do artigo $1^{\circ}$, III, da Carta Magna, imanente a todo o ordenamento jurídico. 
A percepção da amplitude da definição da dignidade da pessoa humana pode ser estimada no voto do excelentíssimo ministro do Supremo Tribunal Federal, ao decidir se a Lei de Anistia violaria preceito fundamental. Veja-se:

[...] a dignidade da pessoa humana precede a Constituição de 1988 e esta não poderia ter sido contrariada, em seu art. $1^{\circ}$, III, anteriormente a sua vigência. A arguente desqualifica fatos históricos que antecederam a aprovação, pelo Congresso Nacional, da Lei 6.683/1979. [...] A inicial ignora o momento talvez mais importante da luta pela redemocratização do país, o da batalha da anistia, autêntica batalha. Toda a gente que conhece nossa História sabe que esse acordo político existiu, resultando no texto da Lei 6.683/1979. [...] Tem razão a arguente ao afirmar que a dignidade não tem preço. As coisas têm preço, as pessoas têm dignidade. A dignidade não tem preço, vale para todos quantos participam do humano. Estamos, todavia, em perigo quando alguém se arroga o direito de tomar o que pertence à dignidade da pessoa humana como um seu valor (valor de quem se arrogue a tanto). É que, então, o valor do humano assume forma na substância e medida de quem o afirme e o pretende impor na qualidade e quantidade em que o mensure. Então o valor da dignidade da pessoa humana já não será mais valor do humano, de todos quantos pertencem à humanidade, porém de quem o proclame conforme o seu critério particular. Estamos então em perigo, submissos à tirania dos valores. [...] Sem de qualquer modo negar o que diz a arguente ao proclamar que a dignidade não tem preço (o que subscrevo), tenho que a indignidade que o cometimento de qualquer crime expressa não pode ser retribuída com a proclamação de que o instituto da anistia viola a dignidade humana. [...] O argumento descolado da dignidade da pessoa humana para afirmar a invalidade da conexão criminal que aproveitaria aos agentes políticos que praticaram crimes comuns contra opositores políticos, presos ou não, durante o regime militar, esse argumento não prospera (ADPF 153, voto do Rel. Min. Eros Grau, julgamento em 29-4-2010, Plenário, DJE de 6-8-2010) (SUPREMO..., 2010).

A teoria que propugna o Capitalismo Humanista pressupõe que a observância dos direitos humanos, a fim de garantir a dignidade da 
pessoa humana prevista no texto constitucional, pode ser alinhavada à livre iniciativa e à propriedade privada dos meios de produção.

Prega-se que não existe antagonismo entre o progresso econômico e a garantia da dignidade da pessoa humana, e que, havendo conflito na solução de tal equação, cujo resultado é sempre a justiça econômica substancial, deverá haver a adoção da lei universal da fraternidade como critério de resolução.

\section{Perspectivas para a transformação do capitalismo como sistema econômico}

Os adeptos da teoria do Capitalismo Humanista sustentam que a lei universal da fraternidade é imanente e deve ser aplicada indiscriminadamente. Contudo, há visões distorcidas da fraternidade, aliando seu conceito a religião, bondade, sacrifício pessoal e assistencialismo. A fraternidade implica aplicação dos direitos humanos a todos os sujeitos e orienta toda e qualquer relação jurídica.

Não se confunda fraternidade com caridade, pois a primeira implica a existência de alteridade. Não se trata meramente de fazer o bem, mas sim de se colocar no lugar do outro, tê-lo como verdadeiro irmão.

A diferença é latente, a teor dos conceitos extraídos do Dicionário Aulete (2011):

(fra.ter.ni.da.de) sf. 1. Convivência harmoniosa e afetiva entre as pessoas. 2. Relação de parentesco entre irmãos; IRMANDADE: “...É meu único parente. Fomos criados juntos [...] E amontoava detalhes daquela fraternidade, exagerando uns, inventando outros..." (Eça de Queirós, O primo Basílio) 3. Amor ao próximo 4. Associação ou comunidade com propósito específico, de cunho religioso, social, cultural ou político [F.: Do lat. fraternitas, atis.]

(ca.ri.da.de) sf. 1. Ação ou resultado de fazer o bem a quem necessita.: Fez uma caridade ao doar os alimentos. 2. Sentimento e atitude de 
apoio aos necessitados: Demonstrava caridade em seu trabalho social. 3. Ajuda ou doação em favor de pessoas necessitadas; ESMOLA 4. Rel. No cristianismo, a terceira das virtudes que nos levam a amar a Deus e ao próximo. 5. Bras. N Cul. Bolo cujos ingredientes são farinha de trigo, manteiga, açúcar e ovos. [F.: Do lat. caritas, atis.]

A fraternidade também se encontra insculpida na Declaração Universal de Direitos Humanos de 1948, adotada e proclamada pela Resolução n. 217 A (III) (ONU, 1948) da Assembléia Geral das Nações Unidas, da qual o Brasil é integrante, recomenda:

\begin{abstract}
Artigo I.
Todos os seres humanos nascem livres e iguais em dignidade e direitos. São dotados de razão e consciência e devem agir em relação uns aos outros com espírito de fraternidade.
\end{abstract}

Não há dúvida, destarte, que a lei universal da fraternidade deve ser observada; porém, como resolver a questão da operacionalização aos casos concretos? A resposta foi abordada por Sayeg (2010), na tese que lhe rendeu o título de livre-docente. Segundo o emérito autor, os critérios para aplicação da lei universal da fraternidade são estabelecidos da forma descrita a seguir:

socorrendo-se da sabedoria do povo, os seis passos na aplicação da lei universal da fraternidade, concretizando os direitos humanos em todas as suas dimensões, que devem ser seguidos pelo magistrado na prestação jurisdicional diante do caso concreto, são: (1) considerar todas as pessoas envolvidas, tendo em mente que se está tratando com seres humanos, que em si têm objetivamente dignidade; (2) buscar perceber a aflição delas diante do caso concreto; (3) ouvir a versão e as razões delas; (4) colocar-se na situação delas; (5) interagir com elas; e (6) aplicar a decisão mais fraterna, que é aquela que concretiza e assegura satisfatividade à dignidade das pessoas humanas envolvidas (SAYEG, 2010, p. 241-245). 
A aplicação da lei universal da fraternidade não se cinge somente ao Poder Judiciário. Qualquer decisão governamental, da Secretária de Direito Econômico, do Conselho Administrativo de Defesa Econômica, da Organização Mundial do Comércio (OMC), enfim, independentemente do ente, público ou privado que o emane, todo o ato deve ser pautado pela lei universal da fraternidade.

É de sublinhar que a justiça econômica e a aplicação da lei universal da fraternidade não consistem em meros conceitos utópicos, impossíveis de serem considerados na realidade fática. Tanto é que o relatório do Conselho de Análise da Sociedade, órgão criado pelo governo francês na tentativa de buscar alternativas para a superação da crise econômica, sob a presidência do filósofo Luc Ferry (2010), dedicou todo um tópico de propostas com base na fraternidade, denominado "um eixo duplo, totalmente prioritário: o auxílio às famílias como único âmbito verdadeiro da solidariedade e até de 'fraternidade' real/afetiva, o auxílio às empresas como único âmbito verdadeiro de luta contra o desemprego" (FERRY, 2010, p. 63).

\section{Considerações finais}

O presente trabalho procurou demonstrar que a livre iniciativa e a propriedade privada dos meios de produção são compatíveis com a justiça econômica. Defende-se que apenas mediante a verificação da justiça distributiva e da justiça comutativa será possível superar os inconvenientes do capitalismo. Desse modo, a dignidade da pessoa humana, com a criação de igualdade de oportunidades, será conformada, constituindo a perspectiva de um novo sistema econômico e social, denominado Capitalismo Humanista. O caminho perpassa, necessariamente, pela adoção de decisões e políticas públicas calcadas na fraternidade. 


\section{Referências}

AULETE. 0 dicionário da língua portuguesa na internet. Disponível em: <http://aulete.uol.com.br/site.php?mdl=aulete_digital〉. Acesso em: 24 jan. 2011.

BRASIL. Constituição (1988). Constituição: República Federativa do Brasil. Brasília, DF: Senado Federal, 1988.

BRASIL. Lei Federal n. 8.078, de 11 de setembro de 1990. Dispõe sobre a proteção do consumidor e dá outras providências. Diário Oficial [da] República Federativa do Brasil, Poder Executivo, Brasília, DF, 12 set. 1990. Disponível em: 〈http://www.planalto.gov.br/ccivil_03/Leis/L8078.htm〉. Acesso em: 24 nov. 2011.

BRASIL. Decreto n. 678, de 6 de novembro de 1992. Promulga a Convenção Americana sobre Direitos Humanos (Pacto de São José da Costa Rica), de 22 de novembro de 1969. Diário Oficial [da] República Federativa do Brasil, Poder Executivo, Brasília, DF, 7 nov. 1992. Disponível em: <http://www.jusbrasil. com.br/legislacao/109746/decreto-678-92>. Acesso em: 24 jan. 2011.

BRASIL. Lei Federal n. 10.406, de 10 de janeiro de 2002. Institui o Código Civil. Diário Oficial [da] República Federativa do Brasil, Poder Executivo, Brasília, DF, 11 jan. 2002. Disponível em: <http://www.receita.fazenda.gov.br/legislacao/ leis/2002/lei10406.htm>. Acesso em: 24 jan. 2011.

COMPARATO, F. K. A afirmação histórica dos direitos humanos. 3. ed. São Paulo: Saraiva, 2004.

FERRY, L. Diante da crise: matérias para uma política de civilização. Rio de Janeiro: Difel, 2010.

FURTADO, C. Formação econômica do Brasil. Edição comemorativa: 50 anos. São Paulo: Companhia das Letras, 2009.

HUBERMAN, L. História da riqueza do homem: do feudalismo ao século XXI. 22. ed. Rio de Janeiro: LTC, 2010. 
MACPHERSON, C. B. Ascensão e queda da justiça econômica e outros ensaios: o papel do Estado, das classes e da propriedade na democracia do século XX. Rio de Janeiro: Paz e Terra, 1991.

MONTORO, A. F. Introdução à ciência do direito. 25. ed. São Paulo: Revista dos Tribunais, 2000.

ORGANIZAÇÃO DAS NAÇÕES UNIDAS - ONU. Direitos humanos: novo nome da liberdade e da democracia. 1948. Disponível em: <http://www.planalto.gov. br/publi_04/COLECAO/DH8.HTM>. Acesso em: 24 jan. 2011.

SAYEG, R. H. Texto de estudos: o capitalismo humanista. São Paulo: Edição do Núcleo do Capitalismo Humanista da PUC-SP, 2010.

SUPREMO TRIBUNAL FEDERAL. Arguição de descumprimento de preceito fundamental 153 distrito federal. Disponível em: <http://redir.stf.jus.br/ paginadorpub/paginador.jsp?docTP=AC\&docID $=612960>$. Acesso em: 28 nov. 2010.

TONETI, E. D. Justiça econômica para todos: doutrina social da igreja e a economia americana. Disponível em: <http://www.teologia-assuncao.br/re-eletronica/numeros/n3/n3_toneti.html>. Acesso em: 24 jan. 2011.

Recebido: 17/07/2011

Received: 07/17/2011

Aprovado: 20/08/2011

Approved: 08/20/2011 